\title{
Misfits, Mavericks and Mainstreams: Drivers of Innovation in the Creative Industries
}

\section{Candace Jones}

University of Edinburgh Business School, UK

\section{Silviya Svejenova}

Copenhagen Business School, Denmark

\& BI Norwegian Business School, Norway

\section{Jesper Strandgaard Pedersen}

Copenhagen Business School, Denmark

\section{Barbara Townley}

Management School, University of St Andrews, UK 


\title{
Misfits, Mavericks and Mainstreams: Drivers of Innovation in the Creative Industries
}

\begin{abstract}
N}=186)$
Creative industries are among the fastest growing and most important sectors of European and North American economies. Their growth depends on continuous innovation, which is important in many industries and also challenging to manage because of inherent tensions. Creative industries, similar to many industries, depend not only on novelty to attract consumers and sustain artistic expression, but also on familiarity to aid comprehension and stabilize demand for cultural products. Agents in the creative industries play with these tensions, generating novelty that shifts industries' labels and boundaries. This tension and agency makes them a valuable setting for advancing theoretical ideas on who drives innovation, from mavericks that challenge conventions to mainstreams that build upon them. We trace this history and then turn to the five papers in the special issue, which examine indepth how mavericks, misfits, mainstreams, and amphibians in various creative domains, from artistic perfumery to choreography, engage with innovation and address tensions. These processes of innovation point to future research that explores and exploits the role of materiality in meaning making, the role of capitals in translation processes and the dynamics of value and evaluation.
\end{abstract}

\section{Keywords}

Creative industries, innovation, convention, agency, art world, field, materiality, meaning, capitals, value, evaluation 
The Creative Industries are a fascinating phenomenon, not least for their cultural, social, economic, and transformative powers (Jones \& Thornton, 2005; Jones, Lorenzen \& Sapsed, 2015a). They consist of individuals and organizations, temporary as well as more permanent, engaged in processes and activities related to conceiving, producing, and distributing creative products such as books, music, films, paintings, or dance and theatre performances, as well as services that create products such as advertising campaigns, critical reviews, or web design; we use products as a short hand for all of these. The importance of creative industries is underscored by their role in $21^{\text {st }}$ century developed economies (Nathan, Pratt \& Rincon-Azner, 2015). Thus, creative industries offer insights into important changes in the global economy and in particular how individuals and organization innovate to drive that change.The central challenge of creative industries, like many industries, is ensuring continuous innovation. The primary tension in the quest for ongoing innovation is whether to protect established markets and stable revenue flows, engaging in incremental innovation, or to create radically novel products that may disrupt the market and firm revenues (Christensen, 1997). In creative industries, this tension involves the competing demands of art and commerce, as well as of novelty and familiarity (Caves, 2000; Lampel, Lant \& Shamsie, 2000). It is played out in cultural products with different degrees of novelty. These products have distinctive aesthetic properties with symbolic functions that enable meaning making, whether entertainment, identity-building or social display (Peltoniemi, 2014). These symbolic functions call for a "symbol-intensive organization" (Lawrence \& Phillips, 2002) and a shift from use value to sign value (DeFillippi, Grabher \& Jones, 2007). Innovation in cultural products resides in their aesthetic properties (e.g., semiotic codes such as styles and genres), as well as in their material bases (e.g., materials, technologies and socio-technical systems) (Jones, Lorenzen \& Sapsed, 2015b).

In recent years, the study of creative industries has gained momentum. What is considered a creative industry changes over time by adding, rather than removing, new industries, and increasing their distinction into 'highbrow' and 'lowbrow', 'serious' and 'popular' (Levine, 1988). For example, the products from less conventional settings, such as architecture (Jones, Maoret, Massa \& Svejenova, 2012; Jones \& Massa, 2013), design (Ravasi \& Stigliani, 2012), fashion (Aspers \& Godart, 2013; Khaire, 2014) and, more recently, artistic perfumes (Endrissat \& Noppeney, 2013), haute cuisine food (Svejenova, Mazza \& Planellas, 2007) and games (Tschang, 2007), have grown in symbolic meaning. Some have even entertained the possibility of considering industries such as telecommunications as a cultural-creative industry, given their use of logics from fashion 
(Djelic \& Ainamo, 2005). Further, research has highlighted the various relationships between people, occasions/places and artifacts through which value is created and assigned, such as the contracts between art and commerce (Caves, 2000), the collaborations among a "motley crew" of contributors (Becker, 1982; Townley, Beech \& McKinlay, 2009), the encounters of creators, intermediaries, and audiences at fairs, festivals, and at competitive events (Moeran \& Strandgaard Pedersen, 2011), or relations among elements of creative products, such as semiotic codes and materiality (Jones et al., 2015b).

While the discussions on labels and definitional boundaries remain unresolved, there seems to be an agreement that these industries are strongly dependent on originality and novelty. This ongoing quest for innovation is, first and foremost, propelled by the creators' own needs for expression (Storr, 1985) and their "effort to break open an avant-garde frontier" (Caves, 2000, p. 204). In addition, this quest is triggered by the audiences' continuous desire for new experiences (Lampel et al., 2000), which are quickly absorbed, thereby generating the need for more creative expression (Martindale, 1990). Last but not least, the pursuit of innovation is also important for the impact it has on the society, as avantgarde brings in alternative perspectives and values (Crane, 1987). However, despite this paramount importance of innovation for value and meaning creation in the creative industries, studies have mainly examined instances of field transformation (Jones \& Thornton, 2005). There is a dearth of systematic understanding of who drives innovation and which networks and industry processes help or hinder the capacity to innovate. That makes this special issue, which focuses on misfits, mavericks, and mainstreams as drivers of innovation particularly timely for advancing theoretical ideas and empirical insights on innovation in a critical setting, such as the creative industries.

In this introduction to the special issue, we first provide a historical evolution and overview of the research on creative industries. Second, we discuss the creative industries as a context of innovation, revealing different drivers of innovation discussed in the literature. Third, we compare the insights and contributions of the five special issue articles for advancing our understanding of drivers of innovation in creative settings. We conclude with some implications and opportunities for further research.

\section{The Evolution of Research on Creative Industries}

Within organization studies, the notion of 'creative industries' has important ancestors in and draws insights from some consolidated traditions, such as those around 'culture industries' (Adorno, 1991), 'cultural industry systems' (Hirsch, 1972; 2000; Jones \& Thornton, 2005; 
Lampel et al., 2000), the 'production of culture' perspective (Peterson \& Berger, 1971; 1975; Peterson, 1997; Peterson \& Anand, 2004), as well as Becker's (1982) work on art worlds, and Bourdieu's (1984) work on the field of cultural production. As a result there is confusion about what is meant by the terms creative or cultural industries. Some scholars refer to both cultural and creative industries (Townley, 2015), or to cultural entrepreneurs in creative industries (Swedberg, 2006). Others argue that the arts and the cultural industries are a subset of the creative industries, as they depend on and derive value from creativity (DeFillippi et al., 2007; Jones et al., 2015b). We trace the historical evolution of these terms and explain why we focus on the creative industries.

The notion of a 'creative industry' appears somewhat oxymoronic. It is an amalgam of two older terms that historically can be traced back to two separate sources. The first term is 'creative arts', as espoused by the Earl of Shaftesbury and Sir Joshua Reynolds in England during the eighteenth century, became associated with an intellectual ideology of 'public art' (Hartley, 2005, pp. 6-7). The second source is 'culture industry', a term coined in 1947 by Max Horkheimer and Theodor Adorno, in their book Dialectic of Enlightenment, to describe the role of media in contemporary society (Moeran \& Strandgaard Pedersen, 2011). For Horkheimer and Adorno the term cultural industry emphasized that cultural products were manufactured (e.g., tailored for consumption by the masses), standardized and rationalized (Adorno, 1991). Both terms — 'creative arts' and 'culture industry'—were originally advocated in opposition to the commercial exploitation of creativity.

Since the 1970s, scholars of cultural industries examined standardized and rationalized processes of cultural production (Hirsch, 1972, 2000), the role of brokerage from academies to the market (White \& White, 1967), and art worlds where individuals collaborate rather than isolated geniuses or generalized taste trends (Becker, 1976; 1982; 2008). Art worlds are comprised of networks of artists, critics and audiences, which link some innovators together and separate others (Jones, 2010). Peterson and colleagues $(1997 ; 2004$; 2008) extended Adorno and Horkheimer's focus on culture as manufactured, developing the 'production of culture perspective' to reveal systems and explain perceptions of authenticity and the evolution of genre categories (Peterson \& Anand, 2004; Lena \& Peterson, 2008).

By the mid-1990s, the term 'creative industries' came into policy and education discourses in Australia and the United Kingdom. These discourses depicted the role of government in cultural policy and the rise of neo-liberal marketization of cultural institutions (Hesmondhalgh \& Pratt, 2005), spawning an array of lists of which industries are "creative" or not (Jones et al., 2015b). During this era, the term 'cultural industries' was replaced by the 
term 'creative industries', captured by the economist Richard Caves' (2000) influential book Creative Industries: Contracts between art and commerce. This shift to creative industries coincided with the growth of the 'new' or 'experience economy', in which value arises out of processing information and meaning creation (e.g. through storytelling) rather than out of the products per se (Moeran \& Strandgaard Pedersen, 2011). In this special issue we engage with the notion of 'creative industries' for three reasons: first, it encompasses cultural production but is not limited to it (Jones et al., 2015b). Second, creative industries focus on the role of culture in market dynamics, enabling comparisons to a broader set of industries that also rely on innovation such as technology and communication. Third, the term cultural has closer associations with tradition, whereas creative has a stronger affinity to innovation, which is at the core of this special issue.

\section{Creative Industries as Innovation Context}

Innovation in the creative industries denotes "those creative efforts that strike the market as unusually distinctive, satisfying, and/or productive in opening new ground" (Caves, 2000, p. 202). Creative products that replicate and reproduce, such as mass consumer products, risk being "boring and featureless" (Becker, 1982, p. 63). In short, innovation demands novelty: creative products must be distinctive and comprehensible (Becker, 1982; Lampel et al., 2000). The propensity for innovation is influenced by the production and reproduction costs of the attempted innovations (Caves, 2000). For example, it is more costly to produce a Wagner opera than a photography exhibition. In addition, innovation involves teaching "audiences something new: a new symbol, a new form, a new mode of presentation" (Becker, 1982, p. 66). Thus, innovation involves individuals in a joint undertaking of training the audiences into those artwork-specific conventions with innovative character, exemplified by modern architecture's trajectory from aberrant to standard (Jones et al., 2012). As with innovation in other settings, a qualification is needed of how radical the newness is and vis-àvis whom/what - e.g., new to the artistic organization, to the art form, and/or to the world (Castañer \& Campos, 2002). Becker (1982) cautions us that most innovations lead to deadends, not producing new art worlds.

Innovation in the creative industries depends on the ongoing pursuit of novelty, which rarely if ever is an act of individual genius. Rather, it is an organized and an organizing activity, which takes on different collaborative forms, such as collaborative circles (Farrell, 2001), projects (DeFillippi, 2015; DeFillippi et al., 2007), art worlds (Becker, 1982), and 
movements (Crane, 1987; Rao et al., 2003; Byrkjeflot et al., 2013). It is a dynamic process that involves field participants, like creators, producers and consumers together with the evaluations by intermediaries.

This field level focus on institutional transformation through the emergence of new categories and practices has been at the core of creative industries' research. Scholars have examined a variety of creative contexts such as the shift from the classical paintings of the Académie des Beaux-Arts to the critic-broker-artist triad of French Impressionism (White \& White, 1965), the identity movement and social transformation that underpinned the haute cuisine's shift from classical to nouvelle cuisine (Rao et al., 2003), the new materials and clients that spurred the creation of the de novo category of modern architecture (Jones et al., 2012), and the avant-garde as the genesis for new categories of painting and art worlds (Crane, 1987). We have extensive studies of institutional transformations in cultural fields with comparisons of before and after, but less clarity on who or what drove these changes, diffused them and how these acts of agency and processes enabled transformation.

Unravelling and specifying the role of agency, with emphasis on the trajectories of different actors' positions, is key to understanding the dynamics of innovation in these industries. We highlight specifically the investigation of drivers of innovation in creative industries for this special issue. The notion of a driver includes both the "one that drives" and the "one that provides impulse and motivation" (Merriam-Webster online dictionary), indicating an emphasis on agency (e.g. on those "rebels with a cause" - cf. Jones et al., 2012), yet not entirely confined by it. In particular, our interest is in the activities and interactions of misfits, mavericks and mainstream actors that, individually and/or collectively, develop new creative practices and processes that are recognized as such by peers, gatekeepers and audiences.

Our view is first and foremost influenced by Howard Becker, whose depiction of creative work as collective action (Becker, 1974) is centred on interaction and collaboration and is inherently agentic, while interested in social structure (Becker, 2008/1982; 1990; 1976). An agentic perspective is mindful of novelty introduced by 'expressive cultural workers' (e.g., artists and creators), as well as by 'routine cultural workers' (Siciliano, forthcoming) whose "hum-drum activities" (Caves, 2000) make art worlds possible. When the expressive and routine workers modify art worlds, they are cultural entrepreneurs (DiMaggio, 1982), who carry out "a novel combination that results in something new and appreciated in the cultural sphere" (Swedberg, 2006, p. 260). These cultural entrepreneurs may be artists who mobilize audiences as part of their art work process (Svejenova, 
Strandgaard Pedersen \& Vives, 2011), architects and designers who express client identity through new material combinations (Jones \& Massa, 2013), intermediaries who seek to discover and launch new artists and styles (Caves, 2000; Hirsch, 1972; 2000), or audiences who partake in co-creation (Parmentier \& Mangematin, 2014).

Becker (1982) identifies three roles and respective positions that may reproduce, modify, or create new conventions: mainstreams, mavericks and misfits. We add a fourth category, which is inspired by Powell and Sandholtz' (2012) notion of amphibious entrepreneurs in the field of biotech and discussed in some of the papers in the special issuethat of amphibians, which highlights the dynamic rather than static nature of Becker's categories and calls for examining actors in time.

Mainstreams are what Becker (1982) calls "integrated professionals." They are trained within the industry, perform with conventions and use existing art worlds. Hence, they are connected among themselves and to conventions. As a result, they produce incremental innovations in creative products. They are also distinguished in status, stratified from low to elite positions, and tend to match their collaborations to their status orderings (Faulkner \& Anderson, 1987). Some of them may become mavericks, violating some conventions. That happens when they propose innovations that the art world does not accept within its boundaries (Becker, 1982). However, initiation of new practices by insiders does not necessarily entail subversion of extant conventions and can build on their position in the field (Gomez \& Bouty, 2011). They may also act as drivers of innovation by engaging in path creation (Garud \& Karnoe, 2001) and initiating "wakes of innovation" when they are prominent actors in the field, as in the case of the renowned architect Frank O. Gehry adopting new digital 3-D representation (Boland, Lyytinen \& Yoo, 2007).

Mavericks are creative actors, who may or may not be trained within the industry, but feel constrained in their work by existing conventions and embark on challenging some of them, while keeping others, in order to avoid incomprehensibility and lack of collaboration (Becker, 1982). An extreme case of a quest for novelty on the fringes of existing art worlds and conventions is that of an artistic avant-garde, which "serves a kind of research and development arm of the culture industry" (Crow, quoted in Crane, 1987, p. 77). In terms of aesthetic innovation, an art movement is avant-garde if it (1) redefines the artistic conventions and organizational context for production, display and distribution, (2) employs new tools and techniques, and (3) provides new definitions of the art object's nature (Crane, 1987). In order to succeed as innovators, mavericks need to mobilize support (Becker, 1982) 
"lining up performers to proselytize for their stylistic innovation" (Caves, 2000, p. 366) or evangelizing for the innovation's consecration (Jones \& Massa, 2013).

Misfits are outsiders who are unable to mobilize collaborators from extant art worlds. They break or do not abide by social rules (Becker, 1963), and may, thereby, have more freedom in the creation of new forms and conventions, deviating from expectations and embarking on path creation (Garud \& Karnoe, 2001). Cardinal (1972) introduced the notion 'outsider art' to describe art conceived outside the confines of the official or mainstream culture. These actors are disconnected, a notion that brings together "the role of the exotic, foreign, and "authentic outsider" (Fine 2003)" and allows taking notice of the role of absent ties for novelty emergence (Phillips, 2011, p. 241). They may contribute novel ideas if discovered and supported by mainstream patrons or dealers (White \& White, 1965).

Amphibians can transit across core and periphery, art and commerce, and other dichotomies; they provide a lot more mobility to the playing field as well as diffuse practices across domains (Powell \& Sandholtz, 2012). Similarly, they are able to move between insider and outsider roles and positions, as in the case of Picasso (Sgourev, 2013) who was uniquely situated to introduce radical innovation because structural conditions allowed for the credibility of drastic experimentation. Such actors inspire others to dare and act as catalysts, bringing together creators of different kind in teams across fields for the realization of artistic visions, such as the case of Diaghilev (Sgourev, 2015).

Mainstreams, mavericks, and misfits are depicted in the literature as rather static positions, with the exception of mainstreams that become mavericks (and vice-versa) (Becker, 1982). However, there is a lot more path creation and less path dependence in relation to these positions. Some artists are very precocious in their innovativeness, while others are late bloomers (Galenson, 2007). Becker (1982) noted that mavericks are former mainstreamers (i.e., integrated professionals) who have found it too constraining to create within the existing conventions. Mavericks, when successful and celebrated, have the tendency to become the new mainstreams, but may seek to sustain being mavericks through optimal distinctiveness (Alvarez et al., 2005) or embark on a new wave of disruptions later in their trajectory. For example, Said (2007) examined how great artists became disruptors at the end of their lives, developing a "new idiom" or "late style", which carries "intransigence, difficulty, and unresolved contradiction" (p. 7). Further, elites may remain central by sponsoring misfits or mavericks and enabling them to acquire new competences and update and preserve their central position. For example, as shown by Powell and Owen-Smith (2012), if elites are open, they can become a force for innovation and change, by forming ties 
with outsiders who do not have prior ties to other elite members. Thus, it is important to examine the temporal dimension of actors who innovate and illuminate their trajectories and the plausible changes in their roles and positions.

Our agentic perspective is not emphasizing a single genius but rather a distributed agency. Actors with different roles and network positions collaborate, compete, or engage in political efforts to mobilize support for new courses of action. The success of innovators and innovation in the creative industries has to do with organizing and persistence - that is constructing "the apparatus of the art world" (Becker, 1982) —as well as with some market forces that are in play (Caves, 2000; Hirsch, 2000). It also involves the need for discovery and recognition by the creative industries' intermediaries, such as critics who evangelize and peers who imitate (Jones \& Massa, 2013) and other evaluative practices and devices (Caves, 2000), some of which takes place at field configuring events, like festivals and fairs (Rüling \& Strandgaard Pedersen, 2010; Moeran \& Strandgaard Pedersen, 2011). New products and business models by creators and producers, recognized and interpreted by intermediaries, build distinctions for the artists and their organizations, while at the same time transforming, incrementally or radically, the creative industries (Svejenova et al., 2010; Jones et al., 2012). This process not only legitimates new styles and forges artists' reputations, but also plants the seeds of obsolescence.

\section{Extending Our Understanding of Innovation in Creative Industries}

Five manuscripts of the 45 submissions constitute this volume, having endured competition and judicious review process. They address, through different theoretical lenses and methods, as well as with reference to different creative and geographical contexts, trajectories of innovation in the creative industries. They investigate how innovation is the interplay of novelty and familiarity, of collective and individual levels in relation to conventions, as well as of practices of and responses to (e)valuation. In that, they also call into question what is meant by innovation, acknowledging degrees of newness and kinds of change, as well as how innovation dynamics matter in and differ across creative settings.

Novelty and familiarity encompass the innovation paradox in the creative industries. Innovators are faced with the difficulty of balancing two contradictory demands: being sufficiently different to be recognized as innovative in form or expression, yet not too different so that categories become difficult to identify (Caves, 2000; Lampel et al., 2000; Alvarez et al., 2005; Lena \& Peterson, 2008). The papers in this volume explore and play 
with the dynamics of these contradictory demands. Artistic practice necessitates some novelty to avoid the sobriquet of being derivative. As noted by Montanari, Scapolan, and Gianecchini (2016) and Slavich and Castellucci (2016), this requires a signature style; its failure to develop indicates a lack of artistic progression individually and, on a wider scale, a stagnating art form. Islam, Endrissat, and Noppeney (2016) argue that innovation pertains to something that is 'hidden', yet recognizable and intuitive: by presenting that which is unknown, it speaks to the known. However, creative products are not neatly packaged. They evoke a spectrum of associations and responses in their audiences, each potentially over-spilling established encoded structure to be suggestive of others. Islam et al. (2016) thus identify innovation as driven by analogical processes, which enable recognition and appreciation of new categories by allowing the innovative to be tied to the familiar. Innovation is thus understood both as inherent within practice and also as a process of translation or mutation. Montanari et al. (2016) also reinforce the idea of innovation as inherent in artistic practice, involving engagement and experimentation. In their study of the Italian choreographer Bigonzetti, conscious motivation in artistic practice is reflected in a need for inclusion, freedom, independence or renewal, rather than the more intuitive, embodied need for rearticulation identified by Islam et al. (2016) in the case of artistic perfumery. For Montanari et al. (2016), while inherent in every artistic endeavour, the sustainability of artistic innovation is identifiable within the trajectory of an artistic career and in relation to a pivotal organization.

The interplay of Collective-individual levels relate to and innovate conventions. Artistic innovation operates at dual levels: the collective, i.e. the shared understandings of cultural artefacts, registered in a cultural frame, and the individual, i.e., embodied understandings where cultural products are appropriated within individual biographies and emotive associations. For Islam et al. (2016) they are 'foundational experiences', intimately associated with identity. This understanding of the dual role of meaning, both collective and individual, has implications for our understanding of innovation. Islam et al.'s (2016) description of the perfume industry establishes the individual within the conventions of collective practice, at once connected to, but also distanced from them. They emphasize that innovation is not a dichotomised choice of either following conventions or deviation from these. Conventions as a form of general rule have to be chosen and then applied, the choice isnecessarily an exercise of individual and collective discretion. Conventions belonging to different mental models can co-exist, as in the case of Indian fashion's local traditional and global models, depicted by Khaire and Richardson-Hall (2016). The appropriate 'collective' 
must be selected, thus Montanari et al. (2016) identify novelty in relation to the conventions of a cultural field, a sub-field or individually, artistically imposed understandings. The assessment of novelty, as Slavich and Castellucci (2016) demonstrate, is always within parameters, with too much deviation from the collective, or too little, being penalised. Similarly, Patriotta and Hirsch (2016), see conventions as institutionalised norms specifying rights and obligations, regulating the artist-audience relationship. The conventions of the art form not only structure the understanding of those who engage in or consume it, but also inform its production and articulation. For these latter authors, innovations are understood as variation or deviation from conventions of the field.

Perhaps we inevitably identify degrees of innovation, if only to avoid the tautological danger of the 'innovation occurs when new forms of activity occurs' type. Drawing on the case of renown Italian choreographer, Montanari et al. (2016) describe four different types of innovation: 'proximal' (exploratory engagement with some novelty), 'fuzzy' (intense experimentation but without a recognizable style), 'established' (fully developed recognizable innovative style) and 'maintained' (limited experimentation with an established style, variations on an established theme). Equally, Patriotta and Hirsch (2016) posit that innovation occurs in relation to cooperative links and/or conventions in an artistic field, thus 'reproduction' or the status quo sees no change in conventions or cooperative links; 'artistic innovation' involves new conventions using the same cooperative links; 'organizational innovation' involves new cooperative links but no change in conventions; whereas 'art world innovation' involves a change in both conventions and networks. For Slavich and Castellucci (2016), the nature of hierarchical relationships is a differentiating factor in relation to innovation in cuisine. In an examination of master/apprentice relationships they demonstrate how the expectation of degree of novelty by critics varies in relation to the nature of the master/apprentice relation, being lower in the case of apprentices to high status chefs, where conformity to a 'master' is more the expectation.

(E)valuation practices and responses are also central to innovation processes. Where evaluative criteria are not ossified, innovation is reflected in the field and settled through convention, which highlights the importance of intermediaries, particularly critics, their valuation practices and the material artefacts that sustain them. Slavich and Castellucci (2016) write 'creative workers need to incorporate their innovations and novel ideas within the canonical, conventional, and familiar art of the master to obtain the best evaluations'. Although haute cuisine may have a unique evaluation system, the authors demonstrate how critics regulate differentiation in the field, and with this, how much innovation is tolerated, by 
whom and how change is transmitted over generations. Khaire and Richardson-Hall (2016) also acknowledge an important element of the consecration process in the presentation of how categories of evaluation, drawn from a primarily western fashion industry, are incorporated into discourse of an Indian fashion magazine, and through this sanctioning, eventually become the dominant model of appreciation and evaluation.

Networks and structural positions are central to innovation processes. Certainly networks and support are identified by Becker as central to success, affecting access to resources including legitimacy. At the same time, however, support from and association with central and high-status actors can have some detrimental effects for the recognition of the innovators. As shown by Slavich and Castellucci (2016), Merton's (1968) well-known Matthew effect is in operation in the creative industries, with high status masters in haute cuisine receiving a disproportionate appreciation and undue credit for their apprentices' innovative achievement. Thus, Becker's original positions are elaborated in our papers and connotatively labelled, the 'insider core' or 'unconventional' mavericks. For example, Patriotta and Hirsch (2016) identify the structured positions of mainstreamers, mavericks, outsiders, and conventional novices, with positions aligned according to conformity or deviance with art world conventions and core/periphery field positions. These structural positions influence the rate of innovation in the creative context. Mainstreamers create formulaic innovation whereas mavericks that engage with the mainstream lead to soft radicalism. Particularly important in Patriotta and Hirsch's (2016) paper is the role of the 'amphibious artists' that function both as insiders and on the 'outside', displaying bridging capital and taking on the role of brokers; thus, greater innovation results from the interstices of different fields. The authors point to Robert Redford as an amphibious artist and entrepreneur, who through the Sundance Film Festival enabled the growth of independent filmmaking, which later became absorbed back into mainstream Hollywood. Similarily, Montanari et al.'s (2016) hint at choreographer Bigonzetti as an amphibian, whose ongoing transitions among different organizations enables an innovative style to emerge. Thus conventional novices are conformers on the periphery; while mainstreamers are conventional but in the core; mavericks or 'tempered radicals' (Meyerson, 2001) are the core but are deviant in their relationship to conventions; while outsiders are both deviant and peripheral.

The dynamics of structural positions and fields are also explored in the papers, revising and updating Becker's (1982) more static framework and revealing types of innovation.. This relational understanding of positions eas constantly changing, have knock on effects, which shape innovation processes. For example, Slavich and Castellucci (2016) 
suggest that creative professionals could be strategic in their positioning; in order to get recognition for their innovative work, they need to be neither a pure mainstream with respect to the master with whom they have apprenticed, nor a pure maverick. Patriotta and Hirsch (2016) define fields as dynamic, with boundaries in flux and artists moving between categories over time. They also highlight the importance of different boundaries, social pertaining to resources and relationships, and symbolic, reflective of fields' typified categories or schemas. Montanari et al. (2016) indicate that positions vary throughout the career, suggesting that fixtures of core or periphery lose their resonance.

Patriotta and Hirsch (2016) suggest that it is the management of cooperative links (the product value chain that translates ideas into products for audiences) through which conventions are managed that affect the prospects of innovation. Montanari et al. (2016) also highlight 'relational work', which captures both the complexity and intensity of relationships, as being an important skill for successful engagement in a field and shaping types of innovation.. The authors build on Daskalaki (2010), moving beyond network analysis' strong versus weak ties, to characterise the different types of relational engagement as broadening (developing new engagements), bonding (high engagement), embedding (engaging in different types of relationships) and disembedding (a decrease in engagement). Thus changes in relational complexity, with the opportunities and freedoms that these grant, all impact artist's experimentation. However, as Khaire and Richardson-Hall (2016) reveal, initially peripheral novelty may have a non-relational diffusion through interdiscursivity, which can permit mavericks to gain visibility and positional status in the field. These papers distinguish field positions and network positions, giving us additional insights into, change and innovation.

Endogenous and exogenous change over time are also explored in these papers.. Although Patriotta and Hirsch (2016) portray the change in American cinema as being largely endogenous, prompted by criticism of the finance model driving the major studios, the changes that gave impetus to the independent movie industry were also sustained by technological change, especially in home and cable TV. Khaire and Richardson-Hall (2016) point to the role of exogenous change in the form of regulatory reform and trade liberalization. They show that fashion as a field of cultural production is not, and cannot be, immune to broader economic changes. Globalization's impact on the understanding of what constitutes fashion well illustrates how trade liberalisation impacts on changing consumption patterns and through this on status valuations and personal identities. The registering of discourse change within a fashion magazine thus mirrors the penetration of globalisation in a 
recipient or host community, in doing so carving out a separate fashion field and a new art world from a predominantly indigent textile one. Indeed it might be argued that innovation constitutes the post-facto acknowledgement of change, be this in the form of genres/styles, structures, resources, or new actors, imposed through time frames and levels of analysis. Hence, innovation is usually recognized in hindsight. Montanari et al. (2016) unravel retrospectively different forms of innovation linked to stages in an artistic career. This is in contrast to Islam et al. who investigate an extant process of the creation of a new scent recorded in situ. Patriotta and Hirsch (2016) raise the issue of longevity of the art world innovation, as the innovation of Sundance becomes more successful and more mainstream with time, giving way to a hybrid major/independent ownership. Time relates to the timespan not only of the innovation but also of its recognition or consecration (Jones \& Massa, 2013). For instance, Khaire and Richardson-Hall (2016) depict the changing conventions in the field of Indian fashion through the content of articles and advertisements in an Indian fashion magazine over time. These papers raise the question of what constitutes recognized innovation in a field and how is it recognised when there is continual change and innovation? As with Theseus' boat, at what moment in the on-going repair and replacement of pieces of wood constitute a new boat? What constitutes innovation within a context of continual change necessarily introduces issues of time and sustainability in identifying its presence.

These issues of time and sustainability raise questions about and prompt a deeper reflection on the theoretical frameworks we have for understanding innovation. There are different schools that permeate the organization studies landscape, as for example the contrasting social networks and institutional framings of change employed by Patriotta and Hirsch (2016) who integrate these with an analysis of both networks and conventions. Similarly, Montanari et al. (2016) emphasize the relational work needed for the realization of artistic innovation. For Islam et al. (2016) materiality plays a central role in accessing the 'difficult-to-articulate familiar experiences' that some would see as the essence of the creative industries. Materiality's relation to embodied knowledge and the way in which artefacts steer actions, is identified as enabling the transference between modalities. Islam et al. (2016) give the example of mood-boards, used in a number of cultural industries, as a way of facilitating transitions or translations between mediums, evoking sense and understandings visually of that which is difficult to grasp in words. They address the neglect of the material that has been recognized in research on creative and institutional processes (Hennion, 2004; Jones, Boxenbaum \& Anthony, 2013) that dominate the studies of creative industries. 
Finally, we must also question the extent to which our concern with, and understanding of, innovation is a function of a particular ontological and epistemological convention, i.e. is a consequence of the way an issue is posed. A focus on innovation seemingly prompts the eternal need for agency with tangible, recognizable and potentially creditable consequences, and from thence a focus on drivers of innovation, and potential variables. Even institutional theory, with its focus on field level innovations and changes over time, relies on the institutional entrepreneur as an explanans of change (DiMaggio, 1988). The need for management is thus ever justified, and justifiable, from such a framework. But to what extent does innovation presuppose agency and what form of agency is pre-supposed in the phrasing of the issue? Is innovation the consequence of conscious endeavour or the inevitable by-product of any on-going activity registered after a period of time? Ultimately, is the identification of the what, who, when, where, why and how of innovation, a series of legitimate questions, or does it reflect the logocentric understanding that has individuals as agents?

\section{Research Opportunities and Implications}

The five papers in the Special Issue contribute to the understanding of innovation processes and drivers with a vantage point on the actors - misfits, mavericks, mainstreams, and amphibians. However, they also point out at the importance of context as a balancing force for that of agency, potentiating or counteracting the innovations, as well as the intermediating materials by which innovation happens. For example, Islam et al. (2016) highlight that in the context of perfumery, materiality is central to the process of innovation; Montari et al.'s (2016) study of dancers showcase embodied materiality, both individually in the dancers as well as their physical interacting in order to enact the choreography. Geographic context is critical for the rise of Indian fashion where colonial Britain originally opened the door and legislation within India enabled the door to be opened once again (Khaire \& Richardson-Hall, 2016). In the concluding part of this introduction we suggest that further work is needed on the role of the context in relation to drivers of innovation, and suggest three possible paths for it: meaning and materiality, value(s) and (e)valuation, and power and capital(s). We briefly outline some ideas on each of them below.

Meaning and materiality. Materiality enables both innovation, providing new opportunities and expression for mavericks and misfits, as well as stability of cultural products that is 
essential for mainstreams. Mavericks create and attempt to promulgate new cultural products and semiotic codes, which in order to diffuse and be translated, need to be available, visible and durable so they can serve as exemplars that spur innovation from others such as churches (Jones \& Massa, 2013), new forms of buildings (Jones et al., 2012), paintings (Sgourev, 2013) or dance (Sgourev, 2015). Materiality also stabilizes meanings by encoding them into durable form that can be shared and preserved - whether digital books, buildings, symphonic performances or dances. Materiality leaves a trail of what meanings are encoded by whom. For example, buildings require professionals and craftsmen whereas digital media necessitates software programmers or twitter writers. It also defines access to cultural products in the form of restricted circulation such as paintings and rare books for the privileged versus webpages and twitter feeds for the masses in developed countries. Materiality enables an archival record by which we can trace innovation and innovators. As such, by examining materiality in creative industries, we can raise and explore critical questions such as under what conditions do familiar forms become the genesis for creative rebellion out of which mavericks craft new art worlds? Or how does materiality help to stabilize new art forms and facilitate their acceptance as mainstream creative products?

By investigating the relations among stability and change in semiotic codes and material base, we can flesh out points of friction and tension that may drive innovation, from incremental to radical. Historically, new materials have enabled new forms of symbolic expression such as the rise of skyscrapers and the creation of a new aesthetic such as modernism (Jones et al., 2012). In a more contemporary vein, the invention of new mediating material forms, such as digitization, may liberate creatives to find or erect new art worlds such as animation films or digital photography, but may also create new constraints in the form of algorithms and programming as requisite skills for producing artwork. The dominance or similarity of material and semiotic forms within a creative industry such as box office hit action films may also become the constraining backdrop against which independent artists strike out in search of novelty rather than formulaic expression. The relation among materiality, semiotic codes and meaning making are ripe for future research and exploration.

Finally, materiality enables us to examine the complex interplay and complementary roles of creative actors and organizations in promoting innovation in creative industries. For example, a recent show of innovation in high tech fashion at the Museum of Fine Arts in Boston (http://www.mfa.org/news/techstyle) demonstrates the interplay of cultural industries, where an established high cultural mainstream organization showcases innovation of another creative industry — fashion and fashion designers — who collaborate with computer 
programmers and material scientists to reinterpret old semiotic codes with new materials (e.g., a dress that shifts shape due to sensors that read body heat) or create new semiotic codes from new material forms such as metallic prosthetics as identity statement or an elegant evening gown in the form of a wave and made from hard plastic. Innovation from these complementary roles highlight Becker's insight of art worlds as collaborative, and also a pathway for studying innovation through roles, knowledge in roles and their relations.

Value(s) and (e)valuation. Values, valuation and evaluative practices constitute a significant part of the innovative context for mavericks, mainstreams and misfits in the cultural-creative industries. As Simmel (1978) has reminded us, value is never an inherent property of objects, but arises from a judgement made about those objects by artistic creators, producers or cultural market intermediaries whose whole life consist in experiencing and judging values. In other words, these agents and, in particular, cultural or market intermediaries are 'involved in the production of value and desire' (Matthews \& Maguire 2014, p.11). Cultural-creative products and services elude mechanistic and systematic evaluation (Caves, 2000; Lampel et al. 2000) and call for a complex mixture of formalized knowledge, informal reference, experience, taste and personal judgment because 'markets of singularities could not function' without evaluation by experts (Karpik, 2010, p.46).

Evaluation and evaluative practices have over the years received attention from social science scholars in general and in particular in the fields of education and research (e.g. Heimer, 2001; Lamont, 2009; Wedlin, 2010). The theoretical contributions address the complexity and variety of the processes, and describe different approaches to evaluation perused in the field (e.g. Lamont, 2012; Stark, 2009). Recently also evaluation of culturalcreative products and services has received attention (e.g. Moeran \& Christensen, 2013; Christensen \& Strandgaard Pedersen, 2013; Strandgaard Pedersen et al., 2013; Khaire, 2014; Maguire \& Matthews, 2014). These studies agree on making an analytical distinction between valuation practices (creating and assigning worth or value) and evaluation practices (forms and procedures for assessing how an entity obtain a certain type of worth recognized in the good), even though the two processes are intertwined in practice (Lamont, 2012; Vatin, 2013). Thus, evaluating a product or service entails a simultaneous process of assessing and assigning value to the product or service in question, bridging artistic recognition and commercial outcome as, for example in the case of film festivals (Mezias et al., 2011).

In order to deal with the problem of evaluating intangible, experiential and highly subjective products and services (and making decisions based on this) a variety of devices 
and ways of performing evaluative practices have been invented (e.g. individual critics, juries and committees, rating and ranking systems, and user voting), but we know little about these forms and how they interact. Thus, one research agenda could be constituted by studies on how various evaluative practices and devices assess 'innovation' and are distributed, practiced and interact in relation to respectively mavericks, mainstreams, misfits and amphibians, across a variety of cultural-creative industries and contexts. A second research agenda could entail studies of the evaluative practices and devices by which cultural intermediaries construct legitimacy for products, producers or creators (mavericks, mainstreams, misfits or amphibians), and for themselves, examining whether differences exist between what devices and practices they perform according to the various categories.

Power and capital(s). The third path for further research involves the concepts of agency that inform our understandings of innovation. While our interest in misfits, mavericks and mainstream actors is informed by Becker's work, it is perhaps instructive to remind ourselves of some of the theoretical insights that might be gained from other lenses. Given the motifs that are examined by Becker and in these papers - field, positions, networks, core and periphery etc. - the work of Bourdieu is particularly pertinent. Indeed both Becker and the papers might be described as Bourdieu-lite (Prior, 2011). Although the comparison with Bourdieu is eschewed by Becker (Gopnik, 2015; Becker, 2008, p. 385), perhaps unduly influenced by the former's earlier work, the parallels between the two are very strong. Bourdieu's work, however, not only presents an integrated overview of how a field functions, but also makes the important contribution of making power relations explicit. Keen to avoid an interactionist position, Bourdieu's analysis of field dynamics relies on the availability and use of capital. Although often presented as resources, capital may be understood as energy: it is the medium through which positions are attained and struggles organized. Its 'three guises' are: economic (money, assets and property rights); social (the actual and potential resources of durable networks of acquaintance or recognition) and cultural (embodied dispositions, 'cultivated' habits, tastes and knowledge) (Bourdieu, 1986). Symbolic capital, Bourdieu's (1998, p. 85) 'capital with a cognitive base', is 'what counts' or what 'is at stake' in a field: 'the frontier between...the vulgar and the distinguished' (Bourdieu, 1985, p. 735). The configurations of habitus (accumulated thought and action), capital and field give rise to practice, in which 'practical sense' is the ability to master what is required to function in a field (Townley, 2014). Becker's art 'world' reflects Bourdieu's fields for whom a field and its logic are formed by the field's agents-in the case of art, the producers, critics, 
collectors, middlemen, curators etc., 'all who have ties with art, who live for art and, to varying degrees, from it' (Bourdieu, 1993, p. 205). However, unlike Becker, fields are nested in hierarchical relations, with some fields, particularly the economic, more dominant than others. From this we may see that Becker's (2008, p. 228) analysis of change linked to cooperative networks and mobilizing support through people and the resources they attract, echoes Bourdieu's social capital. The technical abilities, social skills and conceptual apparatus 'necessary to make it easy to make art' (Becker, 2008, p. 229), and the knowledge of the history of previous attempts to solve the problems of art, appeals to Bourdieu's identification of the necessary cultural capital for art's production and consumption. Becker's identification of reputation and its role in field dynamics surely resembles Bourdieu's symbolic capital. Equally, Becker's (2008, p. 385) conventions, 'people know how things have been done in the past, how things are usually done, and others know all these things too'-the tacit ways of 'seeing and hearing' known by everyone, forming the basis of collective action-reflect Bourdieu's habitus of the field, a knowledge of the 'rules of the game'. As does Becker's 'inertia' that 'disposes people to do the things they've done in the past'.

Becker's analysis is not without its reference to power. Although critical of Bourdieu's undue focus on conflict, Becker (2008/, p. xvi) notes his research focus is guided by looking for trouble, 'for it is only in trouble that the forms of cooperation necessary to make art will be found'. Equally, his understanding of conventions are intimately linked to social structures, while collective action is not solely that of cooperation, but is dependent on what he or she 'can force or persuade others to do' (Becker 2008, p. 379). Becker's focus, however, is on Luke's (1974) first face of power, A getting B to do something they wouldn't usually do. Bourdieu's work is a salutary reminder that the production and consumption of cultural goods and cultural opportunity is neither equally, nor randomly, distributed. Societies come already structured and stratified. Power is integral to this and our analysis must surely be cognizant of this and ask how it affects our explanations. And by extending the understanding and use of capital, Bourdieu also reminds us that 'creative industries' is not such an oxymoron: 'culture is interested and economics is cultural' (Swartz \& Zolberg, 2004, p. 6). A capitals' framework might prompt a series of questions: the balance of capitals that make the production and consumption of creative products possible; the search for difference and its consecration in distinction; the intuitive grasp of power as agents engage in fields and their awareness of who holds power; the functioning of symbolic power to represent, define and legitimize; needing to 'learn the rules of the game'; symbolic struggles, often at 
boundaries, with contestation over that which is valued and what is 'at stake'. Rather than add to a range of questions that might be stimulated by such an approach, however, the contrast between the two does serve to underlie the value of a more explicit and consistent analysis of the role of power in our analyses, whatever their theoretical foundations.

To finish, these three paths for further research - materiality and meaning, value(s) and (e)valuation, and power and capitals - have the potential to expand the conversation on innovation in creative settings and to contribute to sustaining the creative industries as a thriving research domain with opportunities for new insights to come.

\section{References}

Adorno, T.W. (1991). The culture industry: Selected essays on mass culture. London, U.K.: Routledge.

Alvarez, J. L., Mazza, C., Strandgaard Pedersen, J., \& Svejenova, S. (2005). Shielding idiosyncrasy from isomorphic pressures: Towards optimal distinctiveness in European filmmaking. Organization, 12, 863-888.

Aspers, P., \& Godart, F. (2013). Sociology of fashion: Order and change, Annual Review of Sociology, 39, 171-192.

Becker, H.S. (2008). Art worlds. 25th Anniversary edition, updated and expanded. Berkeley, CA: University of California Press.

Becker, H.S. (2006). A dialogue on the ideas of 'world' and 'field' with Alain Pessin. Sociological Forum, 21, 275-86.

Becker, H.S. (1990). Art world revisited. Sociological Forum, 5, 497-502.

Becker, H.S. (1982). Art worlds. Berkeley, CA: University of California Press.

Becker, H.S. (1976). Art worlds and social types. American Behavioral Scientist, 19, 703-18.

Becker, H.S. (1974). Art as collective action. American Sociological Review, 39, 767-76.

Becker, H.S. (1963).Outsiders: Studies in the sociology of deviance. Free Press.

Boland, R.J., Jr., K. Lyytinen, \& Yoo, Y. (2007). Wakes of innovation in project networks: The case of digital 3-D representations in architecture, engineering and construction.

Organization Science, 18(4), 631-647.

Bourdieu, P. (1998). Practical reason. Cambridge, UK: Polity Press.

Bourdieu, P. (1993/1984). The field of cultural production: Essays on art and literature, New York, NY: Columbia University Press.

Bourdieu, P. (1986). The forms of capital. In J Richardson (Ed.). Handbook of Theory and Research for the Sociology of Education (pp. 241-258). New York, NY: Greenwood. 
Bourdieu, P. (1985). Social space and the genesis of groups. Theory and Society, 14(6), 72344.

Byrkjeflot, H., Strandgaard Pedersen, J., \& Svejenova, S. (2013). From label to practice: The process of creating new Nordic Cuisine. Journal of Culinary Science \& Technology, 11, 3655.

Cardinal, R. (1972). Outsider art. Praeger.

Castañer, X., \& Campos, L. (2002). The determinants of artistic innovation: Bringing the role of organizations. Journal of Cultural Economics, 26(1), 29-52.

Caves, R. E. (2000). Creative industries: Contracts between art and commerce. Cambridge, MA: Harvard University Press.

Christensen, C.M. 1997. The innovator's dilemma: when new technologies cause great firms to fail. Cambridge, MA: Harvard Business School Press.

Christensen, B., \& Strandgaard Pedersen, J. 2013. Restaurant rankings in the culinary field. In Christensen, B. and Moeran, B. (eds.), Exploring creativity: Evaluative practices in innovation, design and the arts (pp. 235-259). Cambridge, UK: Cambridge University Press.

Crane, D. (1987). The transformation of the avant-garde: The New York art world, 19401985. Chicago, Ill: The University of Chicago Press.

Daskalaki, M. (2010). Building 'bonds' and 'bridges': Linking tie evolution and network identity in the creative industries. Organization Studies, 31, 1649-1666.

DeFillippi, R. (2015). Managing project-based organization in creative industries. In C. Jones, M. Lorenzen, \& J. Sapsed (Eds.). The Oxford handbook of creative industries, Oxford, UK: Oxford University Press.

DeFillippi, R., Grabher, G., \& Jones, C. (2007). Paradoxes of creativity: Managerial and organizational challenges in the cultural economy. Journal of Organizational Behavior, 28, 511-521.

DiMaggio, P. (1982). Cultural entrepreneurship in nineteenth century Boston: The creation of an organization base for high culture in America. Media, Culture and Society, 4, 33-50.

DiMaggio, P. (1988). Interest and agency in institutional theory. In L. Zucker (Ed.), Institutional patterns and organizations: Culture and Environment: Ballinger Publishing Co.

Djelic, M.-L., \& Ainamo, A. (2005). The telecom industry as cultural industry? The transposition of fashion logics into the field of mobile telephony, Research in the sociology of organizations, $23,45-82$.

Endrissat, N., \& Noppeney, C. (2013). Materializing the immaterial: Relational movements in a perfume's becoming. In Carlile P.; Nicolini D.; Langley A.; Tsoukas H (eds): Perspectives on Process Organization Studies: How matter matters: Objects, artifacts and materiality in Organization Studies, Oxford, UK: Oxford University Press. 
Farrell, M.P. (2001). Collaborative circles: friendship dynamics and creative work. Chicago, Ill: University of Chicago Press.

Faulkner, R. R., \& Anderson, A.B. (1987). Short-term projects and emergent careers: Evidence from Hollywood. American Journal of Sociology, 92, 879-909.

Galenson, D.W. (2007). Old masters and young geniuses: The two life cycles of artistic creativity. Princeton, NJ: Princeton University Press.

Garud, R., \& Karnøe, P. (2001). Path creation as a process of mindful deviation. In R. Garud and P. Karnøe (eds.) Path dependence and creation (pp. 1-38). New York, NY: Lawrence Earlbaum Associates.

Gomez, M-L, \& Bouty, I. (2011). The emergence of an influential practice: food for thought. Organization Studies, 32(7), 921-940.

Gopnik, A. (2015). The outside game: How the sociologist Howard Becker studies the conventions of the unconventional. The New Yorker, Jan 12.

Hartley, J. (2005). Creative industries. In Hartley (ed.), Creative Industries (pp. 1-40). Oxford: Blackwell.

Heimer, C. (2001). Cases and biographies: An essay on routinization and the nature of comparison. Annual Review of Sociology, 27(1), 47-77.

Hennion, A. (2004). Pragmatics of taste. In Jacobs, J. \& Hanrahan, N. (Eds) Blackwell companion to the sociology of culture (pp. 131-144). Oxford, UK: Blackwell.

Hesmondhalgh, D., \& Pratt, A.C. (2005). Cultural industries and cultural policy. International Journal of Cultural Policy, 11(1), 1-13

Hirsch, P.M. (2000). Cultural industries revisited. Organization Science, 11, 356-361.

Hirsch, P.M. (1972). Processing fads and fashions: An organization-set analysis of cultural industry systems. American Journal of Sociology, 77, 639-659.

Islam, G., Endrissat, N., \& Noppeney, C. (2016). Beyond 'the eye' of the beholder: Scent innovation through analogical reconfiguration. Organization Studies, 37(6).

Jones, C. (2010). Finding a place in history: Social and symbolic networks in creative careers. Journal of Organizational Behavior, 31, 726-748.

Jones, C., Boxenbaum, E., \& Anthony, C. (2013). The immateriality of the material in institutional logics. Research in the sociology of organizations, 39, 51-75.

Jones, C., Lorenzen, M., \& Sapsed, J. (2015a). The Oxford handbook of creative industries. Oxford, UK: Oxford University Press.

Jones, C., Lorenzen, M., \& Sapsed, J. (2015b). Creative industries: A typology of change: pp. 4-30. In C. Jones, M. Lorenzen \& J. Sapsed (editors), Oxford handbook of creative industries. Oxford, UK: Oxford University Press 
Jones, C., Maoret, M., Massa, F., \& Svejenova, S. (2012). Rebels with a cause. Organization Science, 23(6), 1523-1545.

Jones, C., \& Massa, F.G. (2013). From novel practice to consecrated exemplar: Unity Temple as a case of institutional evangelizing. Organization Studies, 34(8), 1099-1136.

Jones, C., \& Thornton, P. (2005). Introduction to transformations in cultural industries. Research in the sociology of organizations, 23, ix-xix.

Karpik, L. (2010). Valuing the unique. The economics of singularities. Princeton and Oxford: Princeton University Press.

Khaire, M. (2014). Fashioning an industry: Socio-cognitive processes in the construction of worth of a new industry. Organization Studies, 35(1), 41-74.

Khaire, M. \& Richardson-Hall, E. (2016). Medium and message: Globalization and innovation in the production field of Indian fashion. Organization Studies, 37(6).

Lamont, M. (2009). How professors think. Cambridge, MA: Harvard University Press.

Lamont, M. (2012). Toward a comparative sociology of valuation and evaluation. Sociology, $38(1), 201-221$.

Lampel, J., Lant, T., \& Shamsie, J. (2000). Balancing act: Learning from organizing practices in cultural industries. Organization Science, 11(3), 263-269.

Lawrence, T. B., \& Phillips, N. (2002). Understanding cultural industries. Journal of Management Inquiry, 11(4), 430-441.

Lena, J. C., \& Peterson, R.A. (2008). Classification as culture: Types and trajectories of music genres. American Sociological Review, 73(5), 697-718.

Levine, L. (1988). Highbrow/lowbrow: The emergence of cultural hierarchy in America. Cambridge, MA: Harvard University Press.

Lukes, S. (1974). Power: a radical view. London, UK: Macmillan. Martindale, C. (1990). The clockwork muse: The predictability of artistic change. New Yorkm NY: Basic Books.

Merton, R. (1968). The Matthew effect in science. Science, 159(3810), 56-63.

Meyerson, D.E. (2001). Tempered radicals: How people use difference to inspire change at work. Boston, MA: Harvard Business School Press.

Mezias, S., Strandgaard Pedersen, J, Kim, Ji-Hyun, Svejenova, S. \& Mazza, C. (2011). Transforming film product identities: The status effects of European premier film festivals, 1996-2005. In Moeran, B. and Strandgaard Pedersen, J. (eds.) (2011). Negotiating values in the creative industries: Fairs, festivals and competitive events (pp.169-196). Cambridge, UK: Cambridge University Press.

Moeran, B., \& Strandgaard Pedersen, J. (2011). Negotiating values in the creative industries - Fairs, festivals and competitive events. Cambridge, UK: Cambridge University Press.

Moeran, B., \& Christensen, B. T. (2013). Exploring creativity: Evaluative practices in innovation, design, and the arts. Cambridge, UK: Cambridge University Press. 
Montanari, F., Scapolan, A., \& Gianecchini, M. (2016). 'Absolutely free'? The role of relational work in sustaining artistic innovation. Organization Studies, 37(6).

Nathan, M., Pratt, A. \& Rincon-Azner, A. (2015). Creative economy employment in the EU and UK: A comparative analysis. Nesta, London.

http://www.nesta.org.uk/publications/creative-economy-employment-eu-and-ukcomparative-analysis\#sthash.hLgFhfJT.dpuf

Parmentier, G., \& Mangematin, V. (2014). Orchestrating innovation with user communities in the creative industries. Technological Forecasting and Social Change, 83(1), 40-53.

Patriotta, G., \& Hirsch, P. (2016). Mainstreaming innovation in art worlds: Cooperative links, conventions and amphibious artists. Organization Studies, 37(6).

Peltoniemi, M. (2014). Cultural industries: Product-market characteristics, management challenges and industry dynamics. International Journal of Management Reviews, 17(1), 4168 .

Peterson, R. A. (1997). Creating country music: Fabricating authenticity. Chicago, IL: University of Chicago Press.

Peterson, R.A., \& Anand, N. (2004). The production of culture perspective, Annual Review of Sociology, 30, 311-334.

Peterson, R.A., \& Berger, D.G. (1975). Cycles in symbolic production: The case of popular music. American Sociological Review, 40, 158-173.

Peterson, R.A., \& Berger, D.G. (1971). Entrepreneurship in organizations: Evidence from the popular music industry. Administrative Science Quarterly, 10, 97-106.

Phillips, D. J. (2011). Jazz and the disconnected: City structural disconnectedness and the emergence of the jazz canon (1897 to 1933). American Journal of Sociology, 117(2), 420483.

Powell; W.W., \& Owen-Smith, J. (2012). An open elite arbiters, catalysts, or gatekeepers in the dynamics of industry evolution? In J.F. Padgett and W.W. Powell (eds.) The emergence of organizations and markets (pp. 466-495). Princeton, NJ: Princeton University Press.

Powell, W.W., \& Sandholtz, K. (2012). Amphibious entrepreneurs and the emergence of organizational forms. Strategic Entrepreneurship Journal, 6(2), 94-115.

Prior, N. (2011). Critique and renewal in the sociology of music: Bourdieu and beyond. Cultural Sociology, 5(1), 121-138.

Rao, H., Monin, P., \& Durand, R. (2003). Institutional change in Toque Ville: Nouvelle Cuisine as an identity movement in French gastronomy. American Journal of Sociology, 108(4), 795-843.

Ravasi, D., \& Stigliani, I. (2012). Product design: A review and research agenda for Management Studies, International Journal of Management Reviews, 14, 464-488.

Rüling, C.C., \& Strandgaard Pedersen, J. (2010). Film festival research from an Organizational Studies perspective. Scandinavian Journal of Management, 26(3), 318-323. 
Said, E.W. (2007). On late style. New York, NY: Vintage Books.

Sgourev, S.V. (2015). Brokerage as catalysis: How Diaghilev's Ballets Russes escalated Modernism. Organization Studies, 36(3), 343-361.

Sgourev, S.V. (2013). How Paris gave rise to Cubism (and Picasso): Ambiguity and fragmentation in radical innovation. Organization Science, 24(6), 1601-1617.

Siciliano, M. (forthcoming). Disappearing into the Object: Aesthetic subjectivities and organizational control among routine cultural workers. Organization Studies, published online before print January 29, 2016, doi: 10.1177/0170840615626464.

Simmel, G. (1978). The philosophy of money. London, UK: Routledge and Kegan Paul.

Slavich, B., \& Castellucci, F. (2016). Wishing upon a star: How apprentice-master similarity, status and career stage affect critics' evaluations of former apprentices in the haute cuisine industry. Organization Studies, 37(6).

Stark D. (2009). The sense of dissonance. Princeton, NJ: Princeton University Press.

Storr, A. (1985). The dynamics of creation. New York, NY: Atheneum.

Strandgaard Pedersen, J., Darmer, P., \& Mathieu, C.J. (2013). Bureaucracies and judgmental autonomy: Film consultants in a public film institute. Nordic Journal of Cultural Policy, 4(1), 68-89.

Svejenova, S., Mazza, C., \& Planellas, M. (2007). Cooking up change in haute cuisine: Ferran Adrià as an institutional entrepreneur. Journal of Organizational Behavior, 28, 539561.

Svejenova, S., Planellas, M., \& Vives, L. (2010). An individual business model in the making: a chef's quest for creative freedom. Long Range Planning, 43, 408-430.

Svejenova, S., Strandgaard Pedersen, J., \& Vives, L. (2011). Projects of passion: Lessons for strategy from temporary art. In G. Cattani, S. Ferriani, L. Frederiksen, F. Täube Eds. Projectbased organizing and strategic management, Advances in strategic management, 28 (pp. 501527). Emerald Group.

Swartz, D.L. \& Zolberg, V.L. (2004). Introduction. In D.L.Swartz and V. Zolberg (eds.) After Bourdieu (pp. 1-17). Dordrecht, Netherlands: Kluwer Academic.

Swedberg, R. (2006). The cultural entrepreneur and the creative industries: beginning in Vienna. Journal of Cultural Economics, 30, 243-261.

Townley, B. (2014). Bourdieu and organizational theory: a ghostly apparition? In P. Adler, P du Gay, G. Morgan and M. Reed (Eds.) The Oxford handbook of sociology, social theory, and organization studies.

Townley, B. (2015). Exploring different forms of capitals: Researching capitals in the field of cultural and creative industries. In A. Tatli, M. Özbilgin, and M. Karatas-Özkan (Eds.) Pierre Bourdieu, organization and management (pp.187-206). New York: Routledge, Taylor \& Francis Group. 
Townley, B., Beech, N., \& McKinlay, A. (2009). Managing in the creative industries: managing the motley crew. Human Relations Special Issue, 62, 939-962.

Tschang, F.T. (2007). Balancing the tensions between rationalization and creativity in the video games industry. Organization Science, 18, 989-1005.

Vatin, F. (2013). Valuation as evaluating and valorizing. Valuation Studies, 1(1), 31-50.

Wedlin, L. (2010). Going global: Rankings as rhetorical devices to construct an international field of management education. Management Learning, 42(2), 199-218.

White, H.C., \& White, C.A. (1965). Canvases and careers: Institutional change in the French painting world. New York, NY: Wiley.

Author biographies

Candace Jones is the Chair of Global Creative Enterprise at the University of Edinburgh Business School. Her research interests include creative industries and professional services from the lenses of networks, vocabularies, institutional logics, and materiality. She is currently Past Division Chair for Organization and Management Theory Division, Academy of Management. She is one of the coordinators of the EGOS Standing Working Group on Creative Industries.

Silviya Svejenova is Professor at Copenhagen Business School and Adjunct Professor at BI Norwegian Business School. Her research is on organizing and managing for creativity and innovation. At present, she studies change in executive power structures, transient forms of organizing, and visual and material aspects of innovation. She is the current Chair of EGOS and one of the coordinator of the EGOS Standing Working Group on Creative Industries.

Jesper Strandgaard Pedersen is Professor at Copenhagen Business School and Director of 'Imagine.. Creative Industries Research Centre and Chair of SCANCOR. His research focuses on organizational and institutional change, cultural intermediaries and evaluative practices in the culinary and the filmmaking field. He co-edited 'The Negotiation of Values in the Creative Industries: Fairs, Festivals and Competitive Events', (2011), Cambridge University Press. He is one of the coordinators of the EGOS Standing Working Group on Creative Industries.

Barbara Townley is Professor of Management at the Management School, University of St Andrews. Her work has been reprinted several times and translated into French, German and Portuguese. With colleagues, she is researching into the role of IP in creative SMEs and micro organizations; the role of design in fledgling business start-ups; and strategies of distinction in the Scottish fashion and textile industry. 